PACS 61.48.De

\title{
Scroll structure of carbon nanotubes obtained by the hydrothermal synthesis
}

\author{
E.A. Belenkov ${ }^{1, \dagger}$, F.K. Shabiev ${ }^{2}$ \\ †belenkov@csu.ru \\ ${ }^{1}$ Chelyabinsk State University, 129, Br. Khashirinyh St. 454001, Chelyabinsk, Russia \\ ${ }^{2}$ Tyumen State Oil and Gas University, 38, Volodarskogo St., 625000, Tyumen, Russia
}

In this paper there were studied the structure of multilayer carbon nanotubes by methods of X-ray diffraction and elector microscopy. Test samples were prepared by reacting the porous polycrystalline graphite, heated to 800,850 or $900^{\circ} \mathrm{C}$ with distilled water at room temperature. As a result of X-ray analysis of the carbon residue obtained after evaporation of distilled water was found a slight decrease in the interlayer distance $\mathrm{d}_{002}$ and increase in the average size of coherent scattering regions along the crystallographic c axis of graphite, compared with the same characteristics of the original graphite. This is indicates a small amount of formed carbon nanostructures in the samples at the hydrothermal synthesis. Electron microscopic studies have shown that the samples consist mainly of crystals of the original polycrystalline graphite, which contains on the surface of the tubular scrolled nanostructures. Probably tubular nanostructures was formed by the reaction heated to a high temperature of graphite with distilled water. The model calculations were made by the method of molecular mechanics MM+ and show that the folding of graphene layers in the rolls may occur as a result of the functionalization of graphene layers by not carbon atoms. It is revealed that graphene layers form the structure of scrolled carbon nanotubes as a result of junction hydrogen atoms and/or hydroxyl groups to the graphene layers. As a result it is revealed that the amount of the tubular nanostructures obtained by hydrothermal synthesis is less than $1 \div 2 \%$ of the initial amount of graphite.

Keywords: scroll nanostructures, carbon nanotubes, X-ray analyses, electron microscopy, hydrothermal synthesis.

\section{Introduction}

Properties of carbon materials can vary within a wide range due to changes of carbon atoms coordination in compounds and consequently by changes of atoms hybridization $[1,2]$. For example, carbon nanotubes properties can be changed from metal to semiconductor by changes of carbon nanotubes diameter and carbon-carbon bonds orientation about the tube axis [3, 4]. Existence of carbon nanotubes was proved for the first time in the work [5], their study is of the utmost interest because of their unique physical and technical properties. The carbon nanotubes can be applied as element base of nanoelectronic devices, highstrength construction materials, materials for hydrogen and radioactive wastes storage, etc. [4, 6-9]. The reason nanotubes are not widely used so far is a high cost of their manufacturing and purification. Thus, it is necessary to look for the efficient ways of carbon nanotubes synthesis allowing to get large amounts at low expenditures. One of the possible solution is a hydrothermal method presented in [10].

The aim of this work is an approval of hydrothermal method of synthesis and study of the structure of carbon nanotubes obtained by this method.

\section{Samples and research techniques}

The samples were synthesized according to the method presented in the work [10]. Porous polycrystalline graphite was heated up to 800,850 or $900^{\circ} \mathrm{C}$; then samples were taken from the furnace and put into the vessel with distilled water of ambient temperature $\left(22^{\circ} \mathrm{C}\right)$. As a result of reacting, the heated polycrystalline graphite and distilled water, a part of carbon from heated graphite surface was dissolved in the water. Then water was evaporated and obtained carbon deposition was studied. Samples for electron-microscopic analysis were prepared by dissolving of obtained carbon deposition in ethyl alcohol. Carbon powder dissolved in alcohol was dispersed on carbon films of substrate with a help of sonicator. Electron-microscopic analyses were carried out on transmission electron microscope UEMV-100K according to standard methods [11]. X-ray structure analyses were performed on X-ray diffractometer DRON-3 ( $\mathrm{Cu} \mathrm{k}_{\alpha}$ radiation). Interlayer distances were determined by diffraction lines center of gravity [11]. Regime of diffraction maximum recording ensured error value $\Delta 2 \theta_{1} \sim 0,01^{\circ}$, which resulted in summary error while evaluating the interplanar distance $\Delta \mathrm{d}=0.002 \AA$. Average dimensions of coherent scattering regions (CSR) (L) were calculated by integral 
breadth of lines $(\beta)$ [11], polycrystalline silicon was used as a standard sample. Phase composition was identified by the tables of American Society for Testing Materials (ASTM).

Simulation analysis of mechanism of scroll carbon nanotube forming was performed by the method of molecular mechanics MM+ which is a modified method MM2 [12]. Graphene structures without structural defects like attached atoms and graphene sheets containing these defects were considered as original structures to form nanotubes. Hydrogen atoms were considered as those attached to graphene sheet.

\section{Results and discussion}

XRD pattern of the initial raw carbon material shows some diffraction peaks specific for turbostratic carbon and two iron oxides with the same oxidation rate but different structure $\left(\mathrm{Fe}_{2} \mathrm{O}_{3}(10 \mathrm{R}), \gamma-\mathrm{Fe}_{2} \mathrm{O}_{3}\right)$, there are also pure iron traces (fig. 1).

While analyzing XDR patterns of raw carbon materials obtained as a result of reacting the porous polycrystalline graphite heated up to $800^{\circ} \mathrm{C}$ and distilled water (fig.2), diffraction peaks specific for turbostratic carbon, pure iron and three modifications of iron oxide $\left(\mathrm{Fe}_{2} \mathrm{O}_{3}(10 \mathrm{R}), \mathrm{Fe}_{2} \mathrm{O}_{3}\right.$ (100M), $\gamma-\mathrm{Fe}_{2} \mathrm{O}_{3}$ ) were identified as well.

Table 1 shows phase analysis of raw carbon material and a sample obtained at cooling of graphite, heated up to $800^{\circ} \mathrm{C}$, in water.

Discrepancies of experimentally obtained values for interplanar distances in the samples and ASTM tables for graphite amounted to $3 \%$, and for iron oxides - to $0,2 \%$. Table 1 shows that in the carbon material obtained by reacting of graphite heated up to $800^{\circ} \mathrm{C}$ and distilled water there are

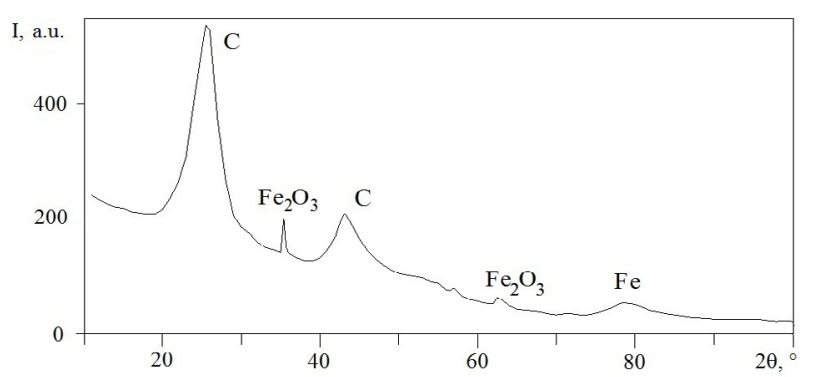

Fig. 1. The XRD pattern of the raw carbon material.

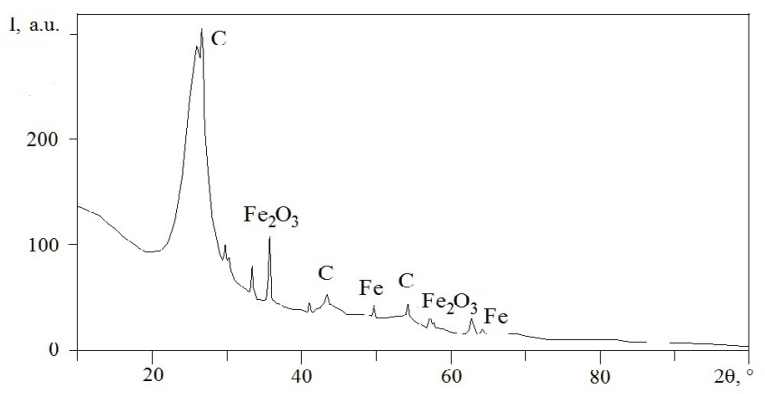

Fig. 2. XRD pattern of carbon material containing carbon nanotubes, obtained by reacting the distilled water with graphite heated up to $800^{\circ} \mathrm{C}$. some additional diffraction peaks corresponding to iron oxide $\mathrm{Fe}_{2} \mathrm{O}_{3}$ (10R), $\gamma-\mathrm{Fe}_{2} \mathrm{O}_{3}$ and those of new modification $\mathrm{Fe}_{2} \mathrm{O}_{3}(100 \mathrm{M})$ which were absent in raw material. Apparently it is due to additional oxidation of iron in raw carbon material while heating in the open air. Intensity of diffraction peaks for iron oxide $\gamma-\mathrm{Fe}_{2} \mathrm{O}_{3}$ in the synthesized sample has been increased for $30 \%$ if compared with those in raw carbon material, while intensity of diffraction peaks corresponding to pure iron has been decreased in the obtained sample (Table 1).

Phase composition of the samples synthesized at 850 and $900^{\circ} \mathrm{C}$ are similar to one synthesized at $800^{\circ} \mathrm{C}$. The profiles of diffraction peak 002 of raw carbon and samples synthesized at different temperatures can be compared in the figure 3. There are no visual differences in the profiles forms. Positions of diffraction peaks $2 \theta_{\mathrm{C}(002)}=25.75-25.76^{\circ}$ of the synthesized samples and $2 \theta_{0}=25.70^{\circ}$ of raw carbon material are slightly different. The position of the peaks estimated according to the center of gravity differs more considerably $2 \theta_{\mathrm{C}(002)}=25.76$ $-25.77^{\circ}$ и $2 \theta_{0}=25.53^{\circ}$.

Table 1. The phase composition of the carbon material containing tubular structures, obtained by reaction of the distilled water with graphite heated up to $800^{\circ} \mathrm{C}$ and the raw carbon material

\begin{tabular}{|c|c|c|c|c|c|}
\hline \multirow[t]{2}{*}{ № } & \multirow[t]{2}{*}{$2 \theta,^{\circ}$} & \multirow[t]{2}{*}{ I, a.u. } & \multirow[t]{2}{*}{$\mathrm{d}, \AA$} & \multicolumn{2}{|l|}{ ASTM } \\
\hline & & & & Phase & hkl \\
\hline \multicolumn{6}{|c|}{ Material containing tubular structures } \\
\hline 1 & 25,90 & 213 & 3,436 & $C(23-64)$ & 002 \\
\hline 2 & 26,60 & 43 & 3,350 & $C(25-284)$ & 002 \\
\hline 3 & 29,75 & 20 & 2,998 & $\mathrm{Fe} 2 \mathrm{O} 3(16-653)$ & \\
\hline 4 & 30,25 & 15 & 2,951 & $\mathrm{Fe} 2 \mathrm{O} 3(4-755)$ & 220 \\
\hline 5 & 33,38 & 28 & 2,681 & $\mathrm{Fe} 2 \mathrm{O} 3(13-534)$ & 104 \\
\hline 6 & 35,75 & 60 & 2,510 & $\begin{array}{l}\mathrm{Fe} 2 \mathrm{O} 3(13-534) \\
\mathrm{Fe} 2 \mathrm{O} 3(4-755)\end{array}$ & $\begin{array}{l}110 \\
311\end{array}$ \\
\hline 7 & 41,00 & 8 & 2,199 & $\mathrm{Fe} 2 \mathrm{O} 3(13-534)$ & 113 \\
\hline 8 & 43,45 & 10 & 2,080 & $\begin{array}{c}\mathrm{Fe} 2 \mathrm{O} 3(4-755) \\
\mathrm{C}(25-284)\end{array}$ & $\begin{array}{l}400 \\
101\end{array}$ \\
\hline 9 & 43,50 & 9 & 2,077 & $\mathrm{Fe}(6-696)$ & 110 \\
\hline 10 & 49,72 & 11 & 1,832 & $\mathrm{Fe} 2 \mathrm{O} 3(13-534)$ & 024 \\
\hline 11 & 53,95 & 6 & 1,698 & $C(25-284)$ & 004 \\
\hline 12 & 54,25 & 10 & 1,688 & $\mathrm{Fe} 2 \mathrm{O} 3(13-534)$ & 116 \\
\hline 13 & 57,25 & 12 & 1,607 & $\mathrm{Fe} 2 \mathrm{O} 3(4-755)$ & 511,333 \\
\hline 14 & 57,75 & 5 & 1,595 & $\mathrm{Fe} 2 \mathrm{O} 3(13-534)$ & 018 \\
\hline 15 & 62,75 & 16 & 1,479 & $\mathrm{Fe} 2 \mathrm{O} 3(4-755)$ & 440 \\
\hline 16 & 64,20 & 4 & 1,449 & $\mathrm{Fe}(6-696)$ & 200 \\
\hline \multicolumn{6}{|c|}{ Raw carbon material } \\
\hline 1 & 25,5 & 177 & 3,49 & $C(23-64)$ & 002 \\
\hline 2 & 35,4 & 60 & 2,53 & $\begin{array}{l}\mathrm{Fe} 2 \mathrm{O} 3(4-755) \\
\mathrm{Fe} 2 \mathrm{O} 3(13-534)\end{array}$ & $\begin{array}{l}311 \\
110\end{array}$ \\
\hline 3 & 43,2 & 94 & 2,09 & $\begin{array}{c}\mathrm{Fe} 2 \mathrm{O} 3(4-755) \\
\mathrm{C}(23-64)\end{array}$ & $\begin{array}{l}400 \\
101\end{array}$ \\
\hline 4 & 53,2 & 6 & 1,72 & $\mathrm{Fe} 2 \mathrm{O} 3(4-755)$ & 422 \\
\hline 5 & 57,0 & 8 & 1,61 & $\mathrm{Fe} 2 \mathrm{O} 3(4-755)$ & 511,333 \\
\hline 6 & 62,5 & 11 & 1,48 & $\mathrm{Fe} 2 \mathrm{O} 3(13-534)$ & 214 \\
\hline 7 & 63 & 12 & 1,47 & $\begin{array}{c}\mathrm{Fe} 2 \mathrm{O} 3(4-755) \\
\mathrm{Fe}(6-696)\end{array}$ & $\begin{array}{l}440 \\
200\end{array}$ \\
\hline 8 & 78,6 & 23 & 1,22 & $\mathrm{Fe}(6-696)$ & 211 \\
\hline
\end{tabular}


The analysis of diffraction peaks profile forms 002 determines the parameters of fine structure of carbon compounds in the studied materials. Reflection 002 of raw carbon material and synthesized samples is actually of the same integral intensity (difference is $0.05 \%$ ) which proves approximately the same amount of structurally ordered carbon. Average interplanar distances of the synthesized samples are less than in raw carbon material for 0.031 - $0.034 \AA$ which means that carbon has more ordered structure in the synthesized samples. Integral breadth of the synthesized samples is less of that of raw material for 0.031 - $0.034 \AA$ which is the result of corresponding differences in the average dimensions of coherent scattering regions (CSR): $\mathrm{L}_{\mathrm{C}}=57.0 \AA$ and $\mathrm{L}_{0}=56.6 \AA$, correspondingly, for synthesized samples and raw carbon material.

Figure 4 shows the bright-field images obtained by electron-microscope studies of the synthesized samples. The sample obtained from carbon heated up to $800^{\circ} \mathrm{C}$ shows three typical zones: zone A contains tubular scroll nanostructures, zone $\mathrm{B}$ contains fiber nanostructures, zone $\mathrm{C}$ contains crystallites with graphite-like structure.

Thedimensions of crystallitesand crystallite conglomerates in the $\mathrm{C}$ zone are from 400 to $500 \mathrm{~nm}$. Sometimes, $\mathrm{C}$ zones contact with zones containing scroll structures but the major part of $\mathrm{C}$ zones has no these nanostructures on the surface.

Figure 4 shows distinct region of A type (outlined) containing tubular nanostructures, their scroll structure differs considerably from usual multilayer nanotubes [13]. Earlier hydrothermal methods allowed to obtain only regular carbon nanotubes with cylinder structure [10]. Tubular scroll nanostructures are presented only on the surface of graphitelike crystallite.

Scroll structures are attached to graphite-like crystallite surface by the wide base mainly at right angle to these surfaces. The length of scroll nanostructures is from 30 to 200 $\mathrm{nm}$, diameter is about $10 \mathrm{~nm}$.

Besides, the electron microscopic image obtained at reacting of carbon heated up to $800{ }^{\circ} \mathrm{C}$ and distilled water shows one more specific type of zones (B) with fiber structures. $\mathrm{B}$ zones do not have contacts with A zones, there are some partial overlaps of $\mathrm{B}$ and $\mathrm{C}$ zones. Electron microscopic images of the sample synthesized from carbon heated up to

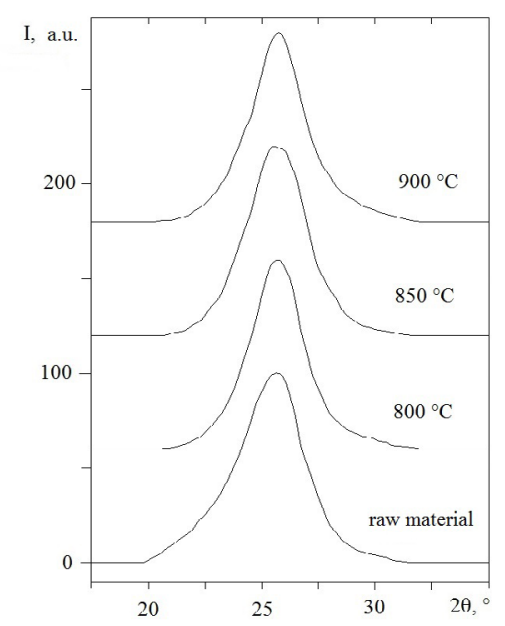

Fig. 3. Diffraction carbon peaks 002 obtained by reacting the distilled water with graphite heated to $800-900^{\circ} \mathrm{C}$ and raw carbon material.
$900{ }^{\circ} \mathrm{C}$ show the zones similar to above mentioned, excepting $\mathrm{B}$ zones. B zones containing fiber structures were not found in this image.

The appearance of carbon nanotubes is mostly probable in the zones $\mathrm{A}$ and $\mathrm{B}$ as they contain needle and fiber structures. $\mathrm{A}$ and $\mathrm{B}$ zones have no contacts, that confirms different mechanism of their forming. B zones are formed in the samples at the temperature below $900{ }^{\circ} \mathrm{C}$.

Mechanism of forming of tubular nanostructures by hydrothermal synthesis at the temperatures $800-900{ }^{\circ} \mathrm{C}$ remains to be unclear. Usual mechanism of nanotubes formation is atom-by-atom assembly from carbon vapour or from carbon atoms dissolved in catalysts metals $[4,6,14]$.

But the temperature of hydrothermal synthesis is not sufficient to disassemble raw graphite layers into separate atoms.

To discover the mechanism of nanotubes forming the simulation studies have been carried out. It was initially assumed that carbon nanotubes appear due to folding of graphene sheets the raw material crystallites are made of [fig.5]. This assumption is based on electron microscopic images (fig.4) where scrolllike nanostructures appear; which can be the result of graphene sheet folding.

Model calculations have been performed in several stages. At the first stage, the ideal graphene sheet fragments, where the edge broken bonds were compensated by atoms of hydrogen, have been calculated. The results obtained at simulation are in conformity with experimental data. The estimated length of carbon-carbon bonds $\mathrm{R}_{\mathrm{C}-\mathrm{C}}=0.140 \mathrm{~nm}$ is rather close to

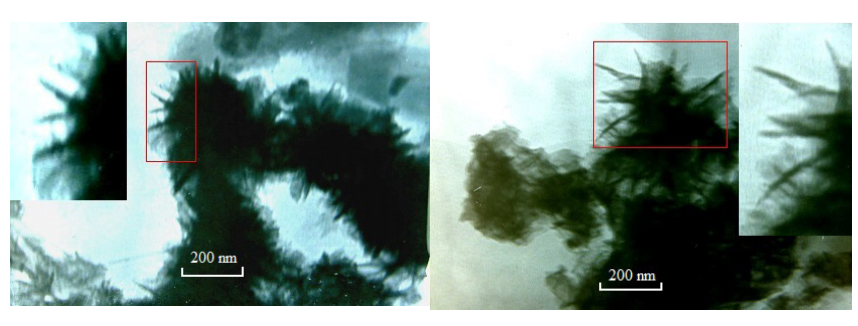

Fig. 4. Electron microscopic images of carbon material obtained from cooling in distilled water graphite heated up to $800^{\circ} \mathrm{C}$. The outlined rectangular zone A contains scrolled structure.
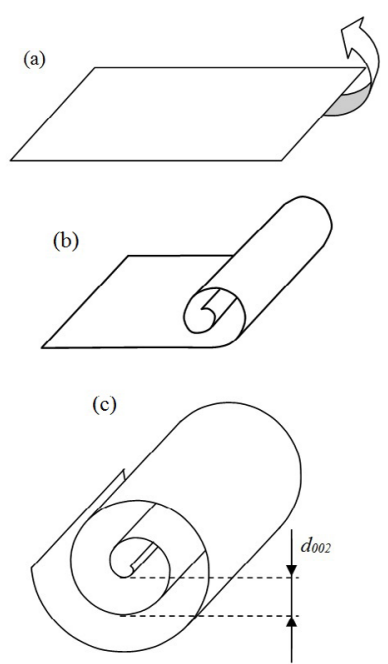

Fig. 5. The structural model of carbon nanotube scrolling: (a) graphene sheet; (b) graphene sheet folding; (c) scrolled carbon nanotube. 
experimentally measured value of the bond length in the graphene layers $\mathrm{R}_{\mathrm{C}-\mathrm{C}}=0.1415 \mathrm{~nm}$ [15], i.e. method $\mathrm{MM}+$ used for calculation allows to find correct structure parameters.

At the second stage, an attempt was made to scroll the graphene sheet. But at geometrical optimization and molecular-dynamics calculations scrolled sheets with dimensions of order $11 \mathrm{~nm}$ always unrolled and made a shape of non deformed flat layer, i.e. scrolled graphene sheet without defects and attached atoms tends to unroll which makes scroll nanotubes forming impossible. Apparently, scroll nanotubes are unrolled if deformation energy at scrolling exceeds the energy of Van der Waal's forces. Thus, the defects like foreign atoms or molecules attached to the graphene sheet are required to fold the graphene sheets (with the dimensions less than 11 $\mathrm{nm}$ ) and to form scroll structure.

Thus, at the third stage a graphene sheet with such defects as hydrogen atoms was simulated. At the hydrothermal synthesis studied in this work, hydrogen atoms formed as a result of reacting the graphite heated up to $800-900{ }^{\circ} \mathrm{C}$ and water and attached to the graphene layers located on the surface of graphite-like crystals from one side (contacting with water) can play the role of molecules providing graphene sheet folding and scroll nanostructures forming. Calculations of these sheet structure show that hydrogen atom attachment resulted in layer folding and scrolling. Figure 6 shows an example of scrolled structure obtained by the $\mathrm{MM}+$ simulation. Interplanar distance in such a structure is $\mathrm{d} \sim 0.335 \mathrm{~nm}$.

Thus, the mechanism of scroll structured nanotubes forming evidently be as follows: graphene sheets comprising the graphite-like crystallites heated up to $800-900^{\circ} \mathrm{C}$ reacting with distilled water attach hydrogen atoms or hydroxyl groups formed as a result of $\mathrm{H}_{2} \mathrm{O}$ molecules dissociation. It resulted in graphene sheets folding, scrolling and scrolled nanotubes forming.

\section{Main results and conclusions}

The difference between parameters of the structure determined by X-ray diffraction in carbon materials containing scroll structures and one of the initial sample, is not considerable which proves small number $(<1-2 \%)$ of formed nanostructures.

Electron-microscopic study of carbon material obtained by cooling of polycristallite graphite heated up to $800-900^{\circ} \mathrm{C}$ in distilled water proves the availability of scroll carbon nanotubes in it.

It was established by the model calculations that scroll

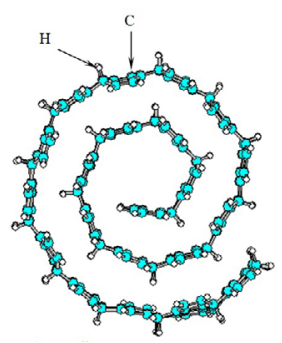

Fig. 6. Geometrically optimized structure of scrolled carbon nanotube, calculated by $\mathrm{MM}+$ method (face plane view, atoms of carbon $(\mathrm{C})$ and hydrogen $(\mathrm{H})$ are indicated by arrows). carbon nanotubes can be formed as a result of graphene sheet scrolling due to attachment of hydrogen atoms or hydroxyl groups to the graphene layer.

\section{References}

1. E.A. Belenkov, V.A. Greshnyakov. New Carbon Materials. 28(4), 273-282 (2013). DOI: 10.1016/S18725805(13)60081-5

2. E.A. Belenkov, V.A. Greshnyakov. Physics of the Solid State. 55(8), 1754-1764 (2013). DOI: 10.1134/ S1063783413080039 [Е.А. Беленков, В.А. Грешняков. Физика твердого тела. 55(8), 1640-1650 (2013)].

3. R. Saito, M. Fujita, G. Dresselhaus, M.S. Dresselhaus. Applied physics letters. 60(18), 2204-2206 (1992). DOI: 10.1063/1.107080

4. P.J.F. Harris. Carbon nanotubes and related structures. Cambridge: Cambridge University Press, 2001, 294 pp.

5. S. Iijima. Nature. 354(6348), 56-58 (1991). DOI:10.1038/354056a0

6. A.V. Eletskii. Physics-Uspekhi, 45(4), 369-402 (2002). DOI: $10.1070 /$ PU2002v045n04ABEH001033 [A.B. Елецкий. УФН, 172(4), 401-438 (2002).]

7. J.A. Baimova, R.T. Murzaev, S.V. Dmitriev. Physics of the Solid State. 56(10), 2010-2016 (2014). [Ю.А. Баимова, Р.Т. Мурзаев, С.В. Дмитриев. Физика твердого тела. 56(10), 1946-1952 (2014).]

8. M.M. Brzhezinskaya, L.A. Pesin, V.M. Morilova, E.M. Baitinger. Physics of the Solid State. 54(9), 19301934 (2012). [М.М. Бржезинская, Л.А. Песин, В.М. Морилова, Е.М. Байтингер. Физика твердого тела. 54(9), 1808-1812 (2012).]

9. M.M. Brzhezinskaya, E.M. Baitinger, E.A. Belenkov, L.M. Svirskaya. Physics of the Solid State, 55(4), 850-854 (2013).

10. Z.H. Kang, E.B. Wang, L. Gao, S.Y. Lian,; M. Jiang; C.W. $\mathrm{Hu}$, L.J. Xu. Am. Chem. Soc. 125(45), 13652-13653 (2003). DOI: $10.1021 / \mathrm{ja} 037399 \mathrm{~m}$

11. A.N. Ivanov, L.N. Rastorgouev, Y.A. Skakov, J.S. Umansky. Crystallography, X-ray analysis and electron microscopy. Moscow: Metallurgy, 1982, 632 p. (in Russian) [A.H. Иванов, Л.Н. Расторгуев, Ю.А. Скаков, Я.С. Уманский. Кристаллография, рентгенография и электронная микроскопия. Москва: Металлургия, 1982, 632 с.]

12. N.L. Allinger, J. Amer. Chem. Sos. 99(25), 8127-8134 (1977). DOI: 10.1021/ja00467a001

13. E.A. Belenkov. Proceedings of the Chelyabinsk Scientific Center of Ural Branch of the Russian Academy of Sciences 10(1), 25-30 (2001). (in Russian) [Е.А. Беленков. Известия Челябинского научного центра УрО РАН. 10(1), 25-30 (2001)].

14. A.V. Eletskii Physics-Uspekhi, 40(9), 899-924 (1997). DOI: 10.1070/PU1997v040n09ABEH000282 [А.В. Елецкий. УФН, 167(9), 945-972 (1997). DOI: $10.3367 /$ UFNr.0167.199709b.0945]

15. A.R. Ubbelohde, F.A. Lewis. Graphite and its crystal compounds. London: Oxford University Press, 1960, $217 \mathrm{pp}$. 